CASE REPORT

\title{
A Man with a Neck Mass, Pleural Effusion and Hypoechoic Masses in the Right Atrium and Ventricle
}

Rabiya Jalii*, Habib ur Rehman

CASE STUDY

A previously healthy 55 -year old Caucasian male presented with a two month history of flu-like symptoms, dry cough, and progressive shortness month history of a slowly growing painless swelling on the left side of his neck. Examination reve normal vital signs, an erythematous, firm but mobile mass on the left side of the neck, and signs of a right sided pleural effusion

Transesophageal echocardiography (TEE) showed a $4.5 \times 3 \mathrm{~cm}$ echodensity in the right ventricle. Furthermore, a $3.5 \times 3.5 \mathrm{~cm}$ sessile echodensity was noted in the right atrium. The left and right ventricles were normal in size and function with an ejection fraction of $60 \%$. There was trace circumferential pericardial effusion.

CT scanning of the neck displayed a fungating and ulcerating soft tissue mass situated at the dermal layer measuring $3.5 \times 1.7 \mathrm{~cm}$ and located above the level of the hyoid at the lower end of the left parotid gland. CT of the chest revealed an extensive bulky filing defect in the right atrum, ight ventricle, and outhow track at the level of the pulmonary valve. Mulcple low densily lesions

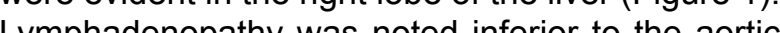

In addition, biopsy of the neck mass revealed a lymphoid infiltrate with atypical features. A majority of cells were positive for CD20, CD10 on immunohistochent negative for CD34,

*To whom correspondence should be addressed

Dr. Rabiya Jalil
Clinical Assistant Professor, Regina Qu'Appelle Health Region Regina, SK, S4P 0W5, Canada approached 100\% for Ki-67. The morphology was atypical Burkitt/Burkitt-like features.

DISCUSSION

ncidence of cardiac neoplasia is very low (1). Most cardiac neoplasms are metastatic, atria myxoma being the most common primary cardiac tumor. Lymphomas constitute $9 \%$ of the total metastases. Cardiac involvement by disseminated non-Hodgkin's lymphoma has been documented in approximately $20 \%$ of autopsy cases to the heart

Burkitt-like lymphoma is a highly aggressive form of non-Hodgkin's lymphoma and assoshort-term survival. Extranoda 作 seldom recognized clinically. Diagnosis is usually

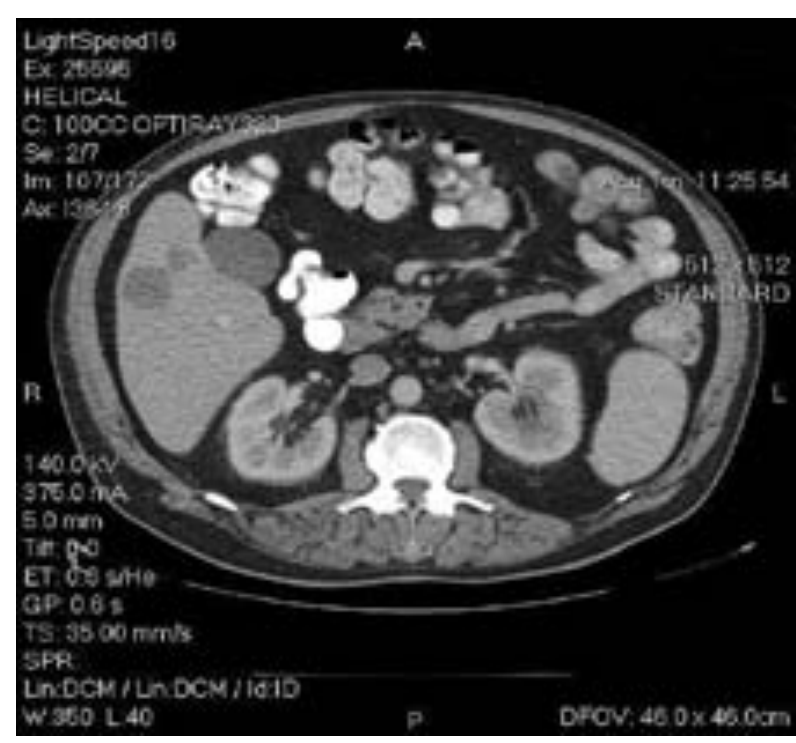

Figure 1:CT inage showing multipe low density lestons in Ine made late because of the non-specific nature of the symptoms. Right-sided heart failure, dyspnea, superior vena cava obstruction, pericardial effusion with or without tamponade, and rhythm disturbancat pre usual presenting features. The average age at presentation is sixty, with a slight male predominance (3). Transesophageal echocardiography (TEE) is supenor to transthoracic echocardiography (TTE) in assessment of cardiac lymphomas and typically shows a hypoechoic mass in the atria effusion. Althoug is associated with pericardial effusion. Although multidetector computed tomography and magnetic resonance imaging will provide information about the staging of disease, biopsy of the mass is needed to make the diagnosis (4). Chemolherapy is the first line trealment, however patients.

Rabiya Jalil (MD 2009) is a graduate of University of Saskatchewan and is currently completing her residency training at the University of Calgary. Her other research interests include medical education and women's health.

Habib ur Rehman (MBBS 1989, FRCPI 2004, FRCPC 2008, FRCP (Glas) 2010, FACP 2011) is a Clinical Assistant Professor at the Department of Medicine at the University of Saskatchewan. He is also Assistant Programme Director for Internal Medicine at the Regin General Hospital and Head of the Medical Teaching Unit.
Rosenthal DS, Braunwald E. Cardiac manifestations of neoplastic disease. In: Braunwald E, ed. Heart disease. A Thascular medicine. 3rd ed. Philadelphia WB Saunders Company, 1988; 1744-1746.

We sies. Arch Pathol Lab Med 1993;117:1027-31.

Ceresoli GL, Ferreri AJ, Bucci E, Ripa C, Ponzoni M, Vila E. Pinmary cardiac lymphoma in immunocompetent patients. diagnostic and

De Filippo M, Chernyschova N, Maffei E, Rovani C, De Blasi M, Beghi C, Zompatori M. Primary cardiac Burkett's typ yymona: transhoracic echocardography, mulitetector

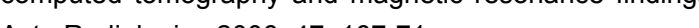

